\title{
Guest-Editorial
}

\section{Dedicated to Eugene Sevin}

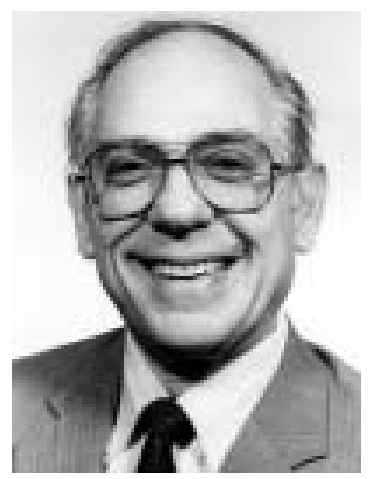

Eugene Sevin

The papers provided in this special issue of the Shock and Vibration Journal reflect well on the remarkable range of contributions of the person to whom it is dedicated: Dr. Eugene Sevin. Over these many decades, Gene Sevin has functioned productively as a researcher in experimental and theoretical mechanics, an educator and professor, a director in planning of complex program elements, and indeed a leader in the field of shock mechanics. The spectrum of his contributions span from basic research into experimental and theoretical mechanics, through to application of complex concepts which spill over into the arena of all types of threats, including the current arena of terror threats. His association with many universities and institutions, such as the Illinois Institute of Technology, Beersheva University in Israel, and the Office of the Secretary of Defense in the Pentagon demonstrate his versatility and accomplishments. Indeed, his service on many National Academy of Engineering and other panels also illustrates his participation and productivity in giving guidance at a very high level to key government programs.

The Shock and Vibration community is indeed fortunate to have Dr. Eugene Sevin as a significant participant, as he has assisted this community in a constructive and positive direction.

Walter Pilkey Nicholas Perrone Thomas Geers Kent Goering 

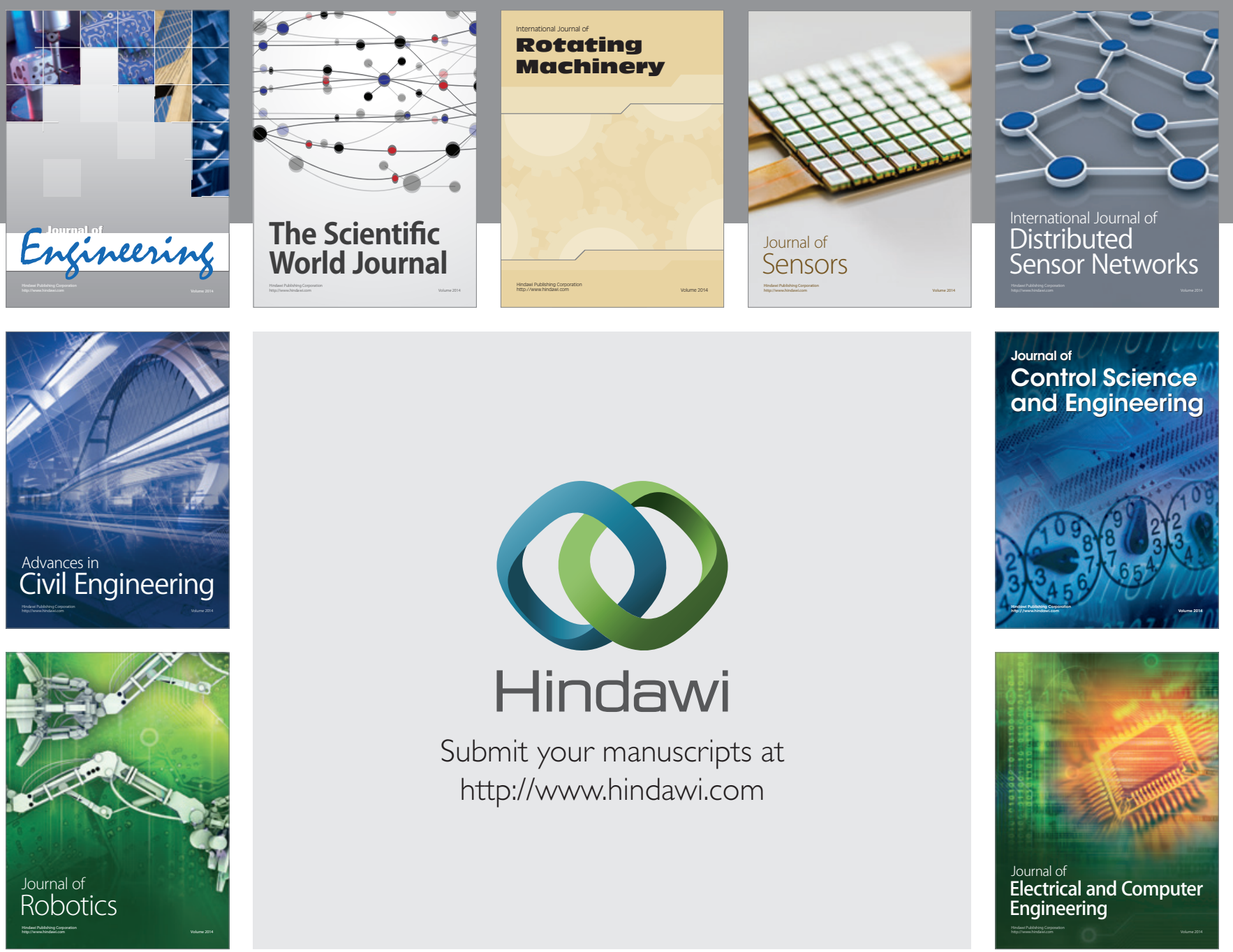

Submit your manuscripts at

http://www.hindawi.com
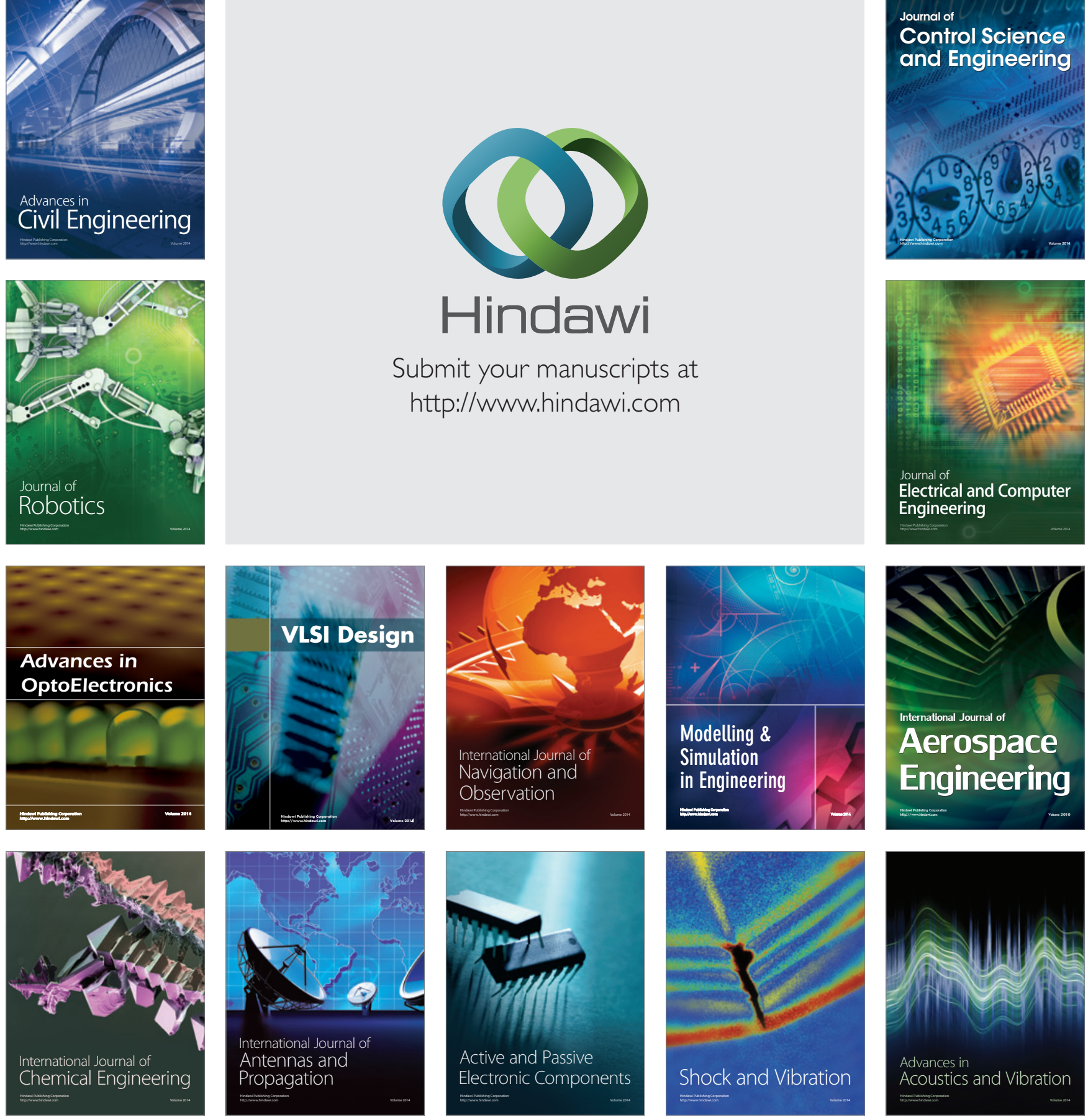